\title{
Mortality associated with timing of admission to and discharge from ICU: a retrospective cohort study
}

Kevin B Laupland ${ }^{1,2}$, Benoit Misset ${ }^{3}$, Bertrand Souweine ${ }^{4}$, Alexis Tabah${ }^{1}$, Elie Azoulay ${ }^{5}$, Dany Goldgran-Toledano ${ }^{6}$ Anne-Sylvie Dumenil ${ }^{7}$, Aurélien Vésin ${ }^{1}$, Samir Jamali ${ }^{8}$, Hatem Kallel ${ }^{9}$, Christophe Clec' ${ }^{10}{ }^{10}$, Michael Darmon ${ }^{11}$, Carole Schwebel ${ }^{11}$ and Jean-Francois Timsit ${ }^{1,11,12^{*}}$

\begin{abstract}
Background: Although the association between mortality and admission to intensive care units (ICU) in the "after hours" (weekends and nights) has been the topic of extensive investigation, the timing of discharge from ICU and outcome has been less well investigated. The objective of this study was to assess effect of timing of admission to and discharge from ICUs and subsequent risk for death.
\end{abstract}

Methods: Adults ( $\geq 18$ years) admitted to French ICUs participating in Outcomerea between January 2006 and November 2010 were included.

Results: Among the 7,380 patients included, 61\% (4,481) were male, the median age was 62 (IQR, 49-75) years, and the median SAPS II score was 40 (IQR, 28-56). Admissions to ICU occurred during weekends (Saturday and Sunday) in 1,708 (23\%) cases, during the night (18:00-07:59) in 3,855 (52\%), and on nights and/or weekends in 4,659 (63\%) cases. Among 5,992 survivors to ICU discharge, 903 (15\%) were discharged on weekends, 659 (11\%) at night, and 1,434 (24\%) on nights and/or weekends. After controlling for a number of co-variates using logistic regression analysis, admission during the after hours was not associated with an increased risk for death. However, patients discharged from ICU on nights were at higher adjusted risk (odds ratio, 1.54; 95\% confidence interval, 1.12-2.11) for death.

Conclusions: In this study, ICU discharge at night but not admission was associated with a significant increased risk for death. Further studies are needed to examine whether minimizing night time discharges from ICU may improve outcome.

\section{Background}

Patients who suffer acute illness and are admitted during the "after hours" (weekends or nights) may be at higher risk for adverse outcome as compared to patients admitted during weekdays [1]. Cavallazzi et al recently conducted a meta-analysis of ten studies conducted in adult ICUs and found that while night time admission was not associated with an increased risk, a small but significant increased risk for death was associated with weekend admission [2]. Since, Kuijsten et al reported a

\footnotetext{
* Correspondence: jftimsit@chu-grenoble.fr

'University of Grenoble 1 (Joseph Fourier) Integrated Research Center U 823 - Albert Bonniot Institute, Rond Point de la Chantourne 38706, La Tronche Cedex, France

Full list of author information is available at the end of the article
}

relative risk for death associated with admission in the afterhours of 1.059 (95\% confidence interval 1.0311.088) among 149,894 admissions to Dutch ICUs [3]. More recently Kevat et al reported on 245,057 admissions to Australian ICUs and found an increased risk for hospital mortality associated with admission during evenings/nights ( $17 \%$ vs. $14 \%$; $<<0.001)$ and during weekends $(20 \%$ vs. $14 \% ; \mathrm{p}<0.001)[4]$. The existence and determinants of afterhours admission effects therefore remains a topic of controversy.

While admission to ICU in the after hours has been closely scrutinized, less attention has been directed to how the timing of discharge from ICU may influence outcome [5-10]. Patient discharges in the afterhours

\section{Biomed Central}


may be a reflection of limited ICU bed capacity and potentially patients may suffer an increased mortality risk due to premature discharge or limited availability of care in the ward setting in the afterhours [5,7-10]. The objective of this study was to investigate whether an after hours effect on mortality may be present among patients admitted to and discharged from ICU.

\section{Methods}

This study utilized an inception cohort design. All data was obtained using the Outcomerea database [11]. All first admissions among adults ( $\geq 18$ years) between January 2006 and November 2010 with complete admission and discharge dates and times were included. According to French law, this study did not require individual patient consent, as it involved research on a previously developed and approved database.

\section{The Outcomerea database}

Outcomerea is a prospective observational study that includes detailed clinical and outcome data on patients admitted to participating French ICUs [11]. In some cases participants in the Outcomerea group have enrolled consecutive patients admitted to ICU and in others sampling has been performed where all consecutive admissions during a period of time during the year or all admissions to certain ICU beds are included. Data included in the Outcomerea database has been collected by senior physicians in the participating ICUs. For each patient, the data were entered into an electronic casereport forms using VIGIREA ${ }^{\circledR}$ and RHEA ${ }^{\circledR}$ data-capture software (OUTCOMEREA ${ }^{\mathrm{TM}}$, Rosny-sous-Bois, France), and all case-report forms were then entered into the OUTCOMEREA ${ }^{\circledR}$ data warehouse. The data-capture software automatically conducts multiple checks for internal consistency of most of the variables at entry in the database. Queries generated by these checks were resolved with the source ICU before incorporation of the new data into the database. At each participating ICU, data quality was controlled by having a senior physician from another participating ICU check a $2 \%$ random sample of the study data. A one-day coding course is organized annually with the study investigators and contrast research organization monitors.

\section{Study protocol}

Once all of the admissions to ICU were identified fulfilling enrollment criteria, the following information were extracted for each patient at presentation: age and sex, admission category (medical, scheduled surgery, or unscheduled surgery). Severity of illness was evaluated at presentation to ICU using the Simplified Acute Physiology Score (SAPS II) and sepsis-related organ failure assessment (SOFA) [12]. Knaus scale definitions were used to record pre-existing chronic organ failures including respiratory, cardiac, hepatic, renal, and immune system failures [13]. The requirement for assisted ventilation, renal replacement therapy, and use of corticosteroids at admission was recorded. The presence of sepsis, severe sepsis, and septic shock was established using standard criteria [14]. The length of stay in ICU and ICU and hospital deaths were recorded. A weekend was a priori defined by the period from 00:00 Saturday to 23:59 Sunday, days as 08:00 to 17:59, and nights as 18:00 to 07:59.

\section{Statistical analysis}

Analysis was performed using Stata version 11.2 (Stata Corp, College Station, TX). To avoid the assessment of multiple outcomes for a single patient, only first ICU presentations were analyzed from patients with multiple ICU admissions. Normally or near-normally distributed variables were reported as means \pm standard deviations (SD) and non-normally distributed variables as medians with inter-quartile ranges (IQR). Means were compared using the Student $\mathrm{t}$ test and medians using the MannWhitney U test. Differences in proportions among categorical data were assessed using Fisher's exact test for pair-wise comparisons and the $\mathrm{chi}^{2}$ test for multiple group trend analysis. Where data missing occurred they were not replaced and are reported with reduced $n$.

Logistic regression models were developed to assess the independent effects of day and time of admission to and discharge from ICU on in-hospital mortality. Factors included in the initial models were admission SAPS II, medical/surgical classification, presence of septic shock, decision to forego life sustaining therapy (DFLST) order, variables found to be significant to the $\mathrm{p}$ $<0.1$ level in univariate analyses, and weekend/weekday and day/evening admission time were included in the initial models. The discharge SOFA score was also included in the discharge timing model. Backward stepwise variable elimination was then performed to develop the most parsimonious models. Discrimination was assessed using the area under the receiver operator characteristic (ROC) curve and calibration using the Hosmer-Lemeshow goodness of fit test.

\section{Results}

A total of 7,380 adult patients were included. Sixty-one percent $(4,481)$ of the patients were male, the median age was 62 (IQR, 49-75) years, and the median SAPS II score was 40 (IQR, 28-56). Admissions were from the emergency department in 3,625 (49\%), inpatient wards in $2,973(40 \%)$, other intensive care areas in $415(6 \%)$, and other/unknown in 367 (5\%); the median stay in hospital prior to ICU admission was 0 IQR, 0-2) days. Admissions to ICU occurred during weekends (Saturday 
and Sunday) in 1,708 (23\%) cases, during the night (18:00-07:59) in 3,855 (52\%), and on nights and/or weekends in 4,659 (63\%) cases. Among 5,992 survivors to ICU discharge, 903 (15\%) were discharged on weekends, $659(11 \%)$ at night, and 1,434 (24\%) on nights and/or weekends.

The overall ICU and in-hospital mortality rates were $1,388 / 7,380$ (19\%) and 1,743/7,380 (24\%), respectively. The crude risk for in-hospital death associated with time of ICU admission was highest in the late morning as shown in Figure 1. On the other hand, the crude risk for in-hospital death after ICU discharge was lowest during the daytime with rates increasing after early evening and were highest in the early morning (Figure 1). Although admission during night $(878 / 3,855 ; 23 \%)$ as compared to day $(865 / 3,525 ; 25 \%) ; \mathrm{p}=0.079)$ hours was not associated with mortality, discharge from ICU at night $(62 / 659 ; 9 \%)$ as compared to daytime (293/5,333; $5 \% ; \mathrm{p}=0.0002)$ hours was associated with subsequent in-hospital mortality.

The crude in-hospital mortality rate varied $(\mathrm{p}=0.045)$ according to the day of the week of ICU admission as shown in Figure 2. An increased crude ICU-mortality $(353 / 1708 ; 21 \%$ vs. $1035 / 5672(18 \%) ; \mathrm{p}=0.026)$ and overall hospital mortality (432/1708; $25 \%$ vs. $1311 / 5672$; $22 \% ; \mathrm{p}=0.005)$ was observed with admission to ICU during weekends as compared to weekdays. The day of discharge of survivors from ICU was not associated ( $\mathrm{p}=$ 0.086) with overall risk for in-hospital death (Figure 2). A weekend ICU discharge was not associated with subsequent in-hospital death (60/903; 7\% vs. 295/5089; 6\%; $\mathrm{p}=0.32$ ). Although there was no increased risk for inhospital death associated with admission during nights and/or weekends as compared to weekday days $(1,096 /$ $4,659$; $24 \%$ vs. $647 / 2,721 ; 24 \%$; $\mathrm{p}=0.82)$, patients discharged from ICU on nights and/or weekends were more likely to die in-hospital as compared to those discharged during weekday days $(111 / 1,434 ; 8 \%$ vs. $244 /$ $4,558 ; 5 \% ; \mathrm{p}=0.001)$.

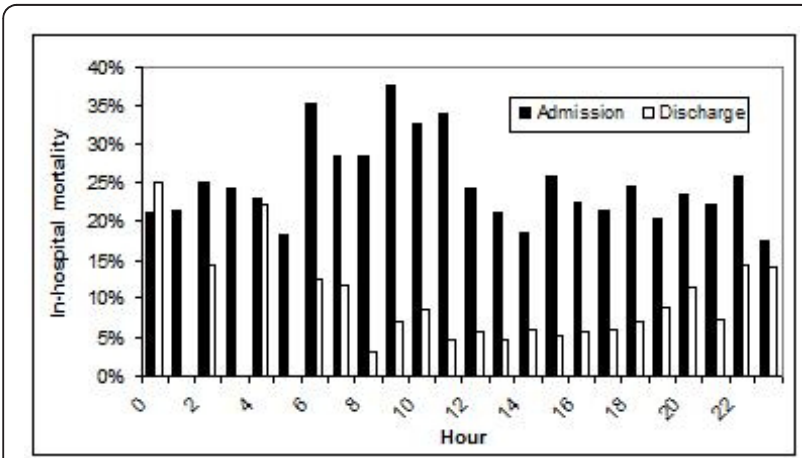

Figure 1 Mortality associated with hour of admission to and discharge from ICU.

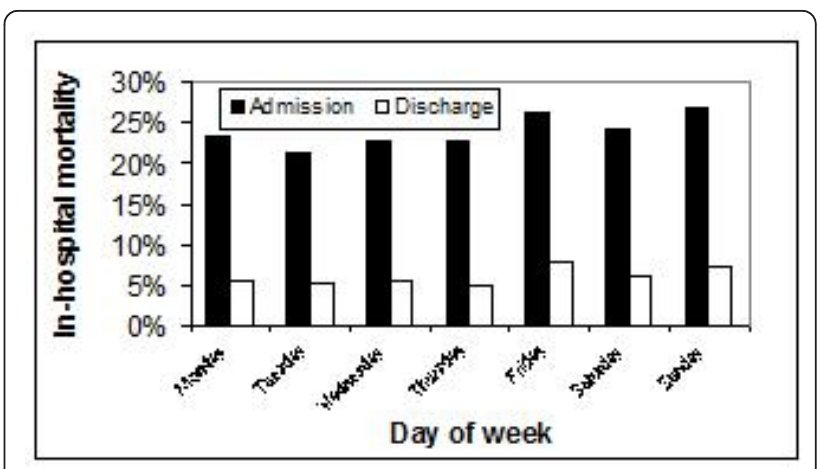

Figure 2 Mortality associated with day of admission to and discharge from ICU.

Patients admitted during weekdays were different based on a number of characteristics from those admitted during nights and/or weekends as shown in Table 1. The overall length of ICU stay was a median of 3 (IQR, 1-7) days and was not different for those admitted on weekends or weekdays $(p=0.075)$ or in the after hours $(\mathrm{p}=0.11)$. Patients discharged during daytime hours during weekdays were also different from those discharged on weekends and/or nights as shown in Table 2. During the course of the ICU stay, 538 patients had a new decision to forego life sustaining therapy (DFLST) order established. New DFLST orders were less likely to be established on a weekend than a week day as shown in Figure 3.

Multivariable logistic regression models were developed to assess factors associated with in-hospital death. In the first model (Table 3), neither admission on evenings or weekends to the ICU was associated with increased risk for in-hospital death. In order to assess the potential effect of the timing of ICU discharge on mortality, a second logistic regression model was developed limited to patients surviving to ICU discharge. As shown in Table 4, discharge from ICU during nights was independently associated with subsequent in-hospital mortality. Discharge during Friday, Saturday, and Sundays was associated with an increased risk for death although this was only statistically significant for Fridays (Table 4).

\section{Discussion}

In this study we found that while most admissions to ICU occur in the after hours and that weekend admissions were associated with a higher crude case-fatality rate, the day of the week or night time admission was not associated with mortality once adjustment for confounding variables was performed (Table 3). However, the timing of discharge was associated with the subsequent risk for in-hospital death especially with night discharges (Table 4). 
Table 1 Characteristics of adults admitted to ICU during weekday/daytime as compared to nights/weekends

\begin{tabular}{|c|c|c|c|}
\hline Factor & Monday to Friday $(n=2,721)$ & $\begin{array}{l}\text { 18:00-07:59 daily and anytime Saturday } \\
\text { or Sunday }(n=4,659)\end{array}$ & P-value \\
\hline Median (IQR) age years & $64(52-76)$ & $62(48-75)$ & $<0.0001$ \\
\hline Male gender & $1073(61 \%)$ & $1832 / 4665(61 \%)$ & 0.92 \\
\hline Median (IQR) & $39(27-56)$ & $41(28-56)$ & 0.0106 \\
\hline \multicolumn{4}{|l|}{ SAPS $\|$} \\
\hline Admit DFLST status & $186(7 \%)$ & $269(6 \%)$ & 0.071 \\
\hline Median (IQR) pre-ICU LOS & $1(0-3)$ & $0(0-1)$ & $<0.0001$ \\
\hline$>2$ days admit prior & $990(36 \%)$ & $1101(24 \%)$ & $<0.0001$ \\
\hline Medical-surgery category & & & $<0.001$ \\
\hline Medical & 1967 (72\%) & $3763(81 \%)$ & \\
\hline Non-scheduled surgery & $287(11 \%)$ & $585(13 \%)$ & \\
\hline Scheduled surgery & $467(17 \%)$ & $311(7 \%)$ & \\
\hline Admitting surgery & & & $<0.001$ \\
\hline Other ICU & $153(6 \%)$ & $262(6 \%)$ & \\
\hline Other ward & $1364(50 \%)$ & 1609 (35\%) & \\
\hline Home & $22(1 \%)$ & $52(1 \%)$ & \\
\hline ER & $1100(40 \%)$ & $2525(54 \%)$ & \\
\hline Other & $82(3 \%)$ & $211(5 \%)$ & \\
\hline Ventilation & & & $<0.001$ \\
\hline None & $1143(42 \%)$ & $2177(47 \%)$ & \\
\hline Non-invasive & $274(10 \%)$ & $428(9 \%)$ & \\
\hline Endotracheal & $1304(48 \%)$ & $2054(44 \%)$ & \\
\hline Main diagnostic category & & & $<0.001$ \\
\hline Respiratory & $662(24 \%)$ & $1082(23 \%)$ & \\
\hline Cardiovascular & $375(14 \%)$ & $692(15 \%)$ & \\
\hline Neuromuscular & $330(12 \%)$ & $694(15 \%)$ & \\
\hline Gastrointestional & $344(13 \%)$ & $648(14 \%)$ & \\
\hline Other surgery & 405 (15\%) & $310(7 \%)$ & \\
\hline Renal, metabolic,toxic & $328(8 \%)$ & $761(16 \%)$ & \\
\hline Infectious & $227(8 \%)$ & $403(9 \%)$ & \\
\hline Other & $50(2 \%)$ & $69(1 \%)$ & \\
\hline \multicolumn{4}{|l|}{ Knaus co-morbidties } \\
\hline hepatic & $176(6 \%)$ & $300(6 \%)$ & 0.96 \\
\hline cardiovascular & $339(12 \%)$ & $631(14 \%)$ & 0.19 \\
\hline respiratory & $363(13 \%)$ & $590(13 \%)$ & 0.41 \\
\hline renal & $173(6 \%)$ & $299(6 \%)$ & 0.96 \\
\hline immune & 409 (15\%) & 700 (15\%) & 1.00 \\
\hline
\end{tabular}

Decision to forego life sustaining therapy (DFLST)

Since the initial reports identifying higher neonatal mortality rates associated with weekend deliveries more than 30 years ago there has been hundreds of subsequent publications evaluating potential after hours effects in wide ranges of patients and settings $[15,16]$. Where after hours effects may be present, it is important issue to define them and explore their determinants. On one hand, an increased risk for death associated with care during different times of the day or week may reflect inconsistencies in availability or quality of care and is a major safety issue that must be addressed. On the other hand, patients admitted in the after hours may be intrinsically at higher risk for death by virtue of a different case-mix, increased severity of illness, or some other unmeasured factor as compared to patients admitted during usual daytime hours.

There is ongoing debate as to whether there may be, and what are the determinants of, after hours admission effects associated with admission to ICUs. In the metaanalysis conducted by Cavallazzi et al, weekend but not night time admission was found to be associated with adverse outcome [2]. However, this study has been followed by a large Dutch study that indicated that weekend but not evening admission was associated with adverse outcome [3]. To further the controversy, an Australian study including nearly one quarter million 
Table 2 Characteristics of adults discharged alive from ICU during weekday/daytime as compared to nights/weekends

\begin{tabular}{|c|c|c|c|}
\hline Factor & $\begin{array}{l}\text { 08:00-17:59 Monday to Friday } \\
(\mathrm{n}=4,558)\end{array}$ & $\begin{array}{l}18: 00-07: 59 \text { daily and anytime Saturday } \\
\text { or Sunday }(n=1,434)\end{array}$ & P-value \\
\hline Median (IQR) age years & $64(52-76)$ & $62(48-75)$ & $<0.0001$ \\
\hline Male gender & $2749(60 \%)$ & $847(59 \%)$ & 0.40 \\
\hline Median admission (IQR) SAPS ॥ & $39(27-56)$ & $41(28-56)$ & 0.0106 \\
\hline Discharge DFLST status & $233(5 \%)$ & $61(4 \%)$ & 0.21 \\
\hline Discharge SOFA & $2(1-4)$ & $2(1-4)$ & 0.14 \\
\hline Median (IQR) ICU LOS & $3(1-7)$ & $2(1-5)$ & $<0.0001$ \\
\hline Medical-surgery category & & & $<0.001$ \\
\hline Medical & 3409 (75\%) & $1132(79 \%)$ & \\
\hline Non-scheduled surgery & $560(12 \%)$ & $167(12 \%)$ & \\
\hline Scheduled surgery & $589(13 \%)$ & $135(9 \%)$ & \\
\hline Main discharge diagnostic category & & & $<0.001$ \\
\hline Respiratory & $1062(23 \%)$ & $291(20 \%)$ & \\
\hline Cardiovascular & $497(11 \%)$ & $176(12 \%)$ & \\
\hline Neuromuscular & $611(13 \%)$ & $184(13 \%)$ & \\
\hline Gastrointestional & $633(14 \%)$ & $206(14 \%)$ & \\
\hline Other surgery & $551(12 \%)$ & $129(9 \%)$ & \\
\hline Renal, metabolic,toxic & $716(16 \%)$ & $284(20 \%)$ & \\
\hline Infectious & 407 (9\%) & $133(9 \%)$ & \\
\hline Other & $81(2 \%)$ & $31(2 \%)$ & \\
\hline \multicolumn{4}{|l|}{ Knaus comorbidities } \\
\hline hepatic & $279(6 \%)$ & $77(5 \%)$ & 0.32 \\
\hline cardiovascular & $539(12 \%)$ & $162(11 \%)$ & 0.61 \\
\hline respiratory & $569(12 \%)$ & 155 (11\%) & 0.094 \\
\hline renal & $279(6 \%)$ & $93(6 \%)$ & 0.62 \\
\hline immune & $638(14 \%)$ & $221(15 \%)$ & 0.20 \\
\hline
\end{tabular}

Decision to forego life sustaining therapy (DFLST)

ICU admissions subsequently was published supporting an increased risk for evening/night and weekend admissions [4]. These differences likely at least reflect heterogeneity among study design and different organisational characteristics among participating study ICUs [2]. A number of factors have been suggested to influence after hours effects not limited to reduced nurse and other healthcare worker staffing, closed versus open ICU models, experience and availability of attending intensivists and/or housestaff, and access to treatments and procedures in the after hours [2,3,5-10]. Generally speaking, among our study ICUs while nursing staffing tends to be comparable or only slightly reduced on weekends and evenings, there are significant decreases in allied healthcare workers including physiotherapists and respiratory therapists, and medical staff including residents, fellows, and attending physicians. It is noteworthy, however, that all of our ICUs employed a closed model and that an attending physician is mandated to remain in-house 24/7.

Although much focus has been placed on potential after hours effects associated with the timing of admission, less attention has been paid to course of care subsequent. From the ICU perspective, few studies have evaluated the effects of the time of discharge from ICU and subsequent outcome. While one study from Finland showed no effect [6], others from Denmark [5], The United Kingdom [7], Australia/New Zealand [8,9], and Canada [10,17] found adverse outcome associated with after hours discharges from the ICU. Few clinicians would agree that discharges late at night would be considered to represent optimal care. In most of our participating ICUs weekend day discharges are discouraged and all night discharges are not standard practice. Many weekend and virtually all night discharges are considered premature discharges. These are nearly always due to limited bed capacity in the ICU and need to admit a more acutely or severely ill patient [18]. It is also notable that we observed an increase in risk for subsequent mortality following discharge on Fridays and an increased risk that was not statistically significantly associated with weekend day discharges. We speculate that this increased risk for death could be reflective of decreased intensity of care on wards on weekends. Unlike ICUs which are resource intensive and designed for 24/7 acute care, many other areas of hospitals are 


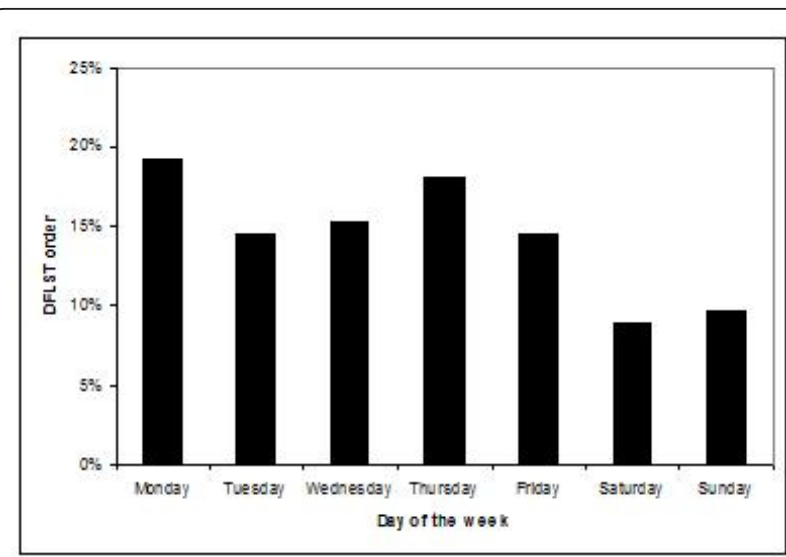

Figure 3 Day of the week for new decision to forgo life sustaining therapy (DFLST) orders after admission to ICU

typically be less prepared for managing acute patients with consistent support over the hours of night and days of the week. It is also important to recognize that placing limitations on patient care such as restrictions on resuscitation may also influence the outcome of patients after discharge from ICU. We identified that new DFLST orders were less likely to be written on weekends (Figure 3 ) and that they were important determinants of outcome (Tables 3 and 4).

There are some study limitations that merit discussion. First, it is important to note that there is no general consensus as to what defines "after hours" or weekend care and definitions have varied among studies to date. Our a priori selected definitions may not necessarily reflect the exact times when staffing or other service delivery changes may occur, and we did not consider national holidays or seasonal variability. It is notable that a post hoc analysis defining a weekend from
Table 4 Logistic regression modeling of factors associated with in-hospital death following ICU discharge

\begin{tabular}{lll}
\hline Factor & $\begin{array}{l}\text { Odds ratio (95\% confidence } \\
\text { interval) }\end{array}$ & P-value \\
\hline Male & $1.30(1.02-1.65)$ & 0.031 \\
SAPS II (per point) & $1.03(1.02-1.03)$ & $<0.001$ \\
$\begin{array}{l}\text { Discharge SOFA score (per } \\
\text { point) }\end{array}$ & $1.19(1.14-1.23)$ & $<0.001$ \\
DFLST order & $4.55(3.34-6.20)$ & $<0.001$ \\
Diagnosis & 1 (reference) & - \\
Other diagnoses & & \\
Cardiovascular disease & $1.50(1.04-2.16)$ & 0.029 \\
Respiratory disease & $1.53(1.11-2.10)$ & 0.008 \\
Gastrointestinal & $1.83(1.30-2.56)$ & $<0.001$ \\
Infection & $1.76(1.20-2.56)$ & 0.003 \\
Discharge day & & - \\
Monday & $1($ reference) & 0.949 \\
Tuesday & $0.99(0.66-1.48)$ & 0.631 \\
Wednesday & $0.91(0.60-1.36)$ & 0.296 \\
Thursday & $0.80(0.53-1.21)$ & 0.046 \\
Friday & $1.45(1.01-2.10)$ & 0.315 \\
Saturday & $1.26(0.80-2.00)$ & 0.193 \\
Sunday & $1.41(0.84-2.35)$ & 0.008 \\
Night discharge & $1.54(1.12-2.11)$ & \\
\hline The model (n 5.992$)$ &
\end{tabular}

The model $(n=5,992)$ had fair discrimination (area under receiver operator characteristic curve 0.771 ) and calibration (goodness of fit $\mathrm{p}=0.4370$ ). Decision to forego life sustaining therapy (DFLST)

Friday at 18:00 to Monday at 07:59 and found that this made no appreciable difference in our conclusions. However, in post hoc analyses examining six-hourly time periods of 00:00-05:59, 06:00-11:59, 12:00-17:59, and 18:00-23:59 (as suggested by the results in Figure 1), crude in-hospital mortality rates were $22 \%, 33 \%, 22 \%$, and $22 \%(\mathrm{p}<0.001)$ associated with admission and were

Table 3 Logistic regression modeling of factors associated with in-hospital death

\begin{tabular}{|c|c|c|}
\hline Factor & Odds ratio ( $95 \%$ confidence interval) & P-value \\
\hline Diagnosis renal/toxic/metabolic vs. other & $0.30(0.23-0.38)$ & $<0.001$ \\
\hline DFLST order & $5.52(4.28-7.12)$ & $<0.001$ \\
\hline SAPS $\|$ (per point) & $1.07(1.06-1.07)$ & $<0.001$ \\
\hline Male gender & $1.31(1.14-1.50)$ & $<0.001$ \\
\hline Pre-ICU hospital stay (per day) & $1.01(1.00-1.02)$ & 0.001 \\
\hline \multicolumn{3}{|l|}{ Admission day } \\
\hline Monday & 1 (reference) & - \\
\hline Tuesday & $0.89(0.69-1.13)$ & 0.337 \\
\hline Wednesday & $1.04(0.81-1.34)$ & 0.737 \\
\hline Thursday & $0.99(0.77-1.27)$ & 0.943 \\
\hline Friday & $1.25(0.98-1.60)$ & 0.078 \\
\hline Saturday & $1.07(0.82-1.38)$ & 0.626 \\
\hline Sunday & $1.06(0.81-1.39)$ & 0.662 \\
\hline Night time admission & $0.94(0.82-1.07)$ & 0.344 \\
\hline
\end{tabular}

The model $(n=7380$ ) had good discrimination (area under receiver operator characteristic curve 0.8543 ) and calibration (goodness of fit $p=0.411$ ). Decision to forego life sustaining therapy (DFLST) 
$11 \%, 6 \%, 5 \%$, and $9 \%(\mathrm{p}=0.002)$ associated with ICU discharge during these periods, respectively. Second, this study was a retrospective review. Although data are collected in a prospective manner in Outcomerea, data were not specifically collected for purposes of this study protocol per se. While we observed no overall effect on outcome associated with timing of admission to ICU, the possibility exists that certain subgroups of patients, timing of pre-ICU care, or differences in provision of care in the pre-ICU setting may have influenced outcome. A third limitation is that because our study is focussed in the ICU environment, we do not have detailed data on subsequent care provided on wards. As a result we may only speculate as to why patients discharged at night suffered higher mortality. Finally, although multiple centres were included in this study, more than one-half of the patients were enrolled from two ICUs with small numbers included from some sites, limiting the ability to assess inter-facility variability.

\section{Conclusions}

In this study we found no association between the timing of admission to ICU and subsequent outcome after controlling for a number of variables in multivariable analysis. However, the timing of discharge, especially during the night was associated with adverse mortality outcome. Further investigation is needed to examine whether minimization of after hours discharges and/or augmentation of ward care post-ICU discharge may improve the ultimate outcome of critical illness.

\footnotetext{
Acknowledgements and Funding

The study was funded by the OUTCOMEREA organization. Contributors

Scientific committee:

Jean-François Timsit (Hôpital Albert Michallon and INSERM U823, Grenoble, France), Elie Azoulay (Medical ICU, Hôpital Saint Louis, Paris, France), Yves Cohen (ICU, Hôpital Avicenne, Bobigny, France), Maïté Garrouste-Orgeas (ICU Hôpital Saint-Joseph, Paris, France), Lilia Soufir (ICU, Hôpital Saint-Joseph, Paris, France), Jean-Ralph Zahar (Microbiology Department, Hôpital Necker, Paris, France), Christophe Adrie (ICU, Hôpital Delafontaine, Saint Denis, France), Michael Darmon (Medical ICU, University hospital St Etienne, France), Bertrand Souweine (CHU Gabriel Montpied, Clermont Ferrand, France), and Christophe Clec'h (ICU, Hôpital Avicenne, Bobigny, and INSERM U823, Grenoble, France)

Biostatistical and informatics expertise: Jean-Francois Timsit (Hôpital Albert Michallon and Integrated research center U823, Grenoble, France), Corinne Alberti (Medical Computer Sciences and Biostatistics Department, Robert Debré, Paris, France), Aurélien Vesin (Integrated research center U823, Grenoble, France), Stephane Ruckly, (Integrated research center U823, Grenoble, France), Christophe Clec'h (ICU, Hôpital Avicenne, Bobigny, and INSERM U823, Grenoble, France), and Didier Nakache (Conservatoire National des Arts et Métiers, Paris, France), Kevin Laupland (Integrated research center U823, Grenoble, France).

Investigators of the Outcomerea database:

Christophe Adrie (ICU, Hôpital Delafontaine, Saint Denis, France and Physiology, Hôpital Cochin, Paris, France), Bernard Allaouchiche (ICU, Edouard Herriot Hospital, Lyon), Claire Ara-Somohano (CHU, Grenoble France), Jean-Pierre Bedos (Medical surgical ICU, André Mignot Hospital, Versailles-Le Chesnay, France), Agnes Bonadona (CHU Grenoble France),
}

Christine Cheval (SICU, Hôpital Saint-Joseph, Paris, France), Jean-Pierre Colin (ICU, Hôpital de Dourdan, Dourdan, France), Michael Darmon (ICU, CHU Saint Etienne), Yohann Dubois (CHU Grenoble, France), Anne-Sylvie Dumenil (Hôpital Antoine Béclère, Clamart France), Adrien Descorps-Declere (Hôpital Antoine Béclère, Clamart France), Rebecca Hamidfar-Roy (CHU Grenoble, France), Samir Jamali (ICU, Hôpital de Dourdan, Dourdan, France), Hatem Khallel (ICU, Cayenne General Hospital), Christian Laplace (ICU, Hôpital Kremlin-Bicêtre, Bicêtre, France), Alexandre Lauttrette (ICU, CHU G Montpied, Clermont-Ferrand), Thierry Lazard (ICU, Hôpital de la Croix Saint-Simon, Paris, France), Eric Le Miere (ICU, Hôpital Louis Mourier, Colombes, France), Laurent Montesino (ICU, Hôpital Bichat, Paris, France), Bruno Mourvillier (ICU, Hôpital Bichat, France), Benoît Misset (ICU, Hôpital Saint-Joseph, Paris, France),

Delphine Moreau (ICU, Hôpital Saint-Louis, Paris, France), Etienne Pigné (ICU, Hôpital Louis Mourier, Colombes, France), Benjamin Planquette (Medical surgical ICU, André Mignot Hospital, Versailles-Le Chesnay, France), Bertrand Souweine (ICU, CHU G Montpied, Clermont-Ferrand), Carole Schwebel (CHU A Michallon, Grenoble, France), Lilia Soufir (Surgical ICU, St Joseph Hospital, Paris, France), Gilles Troché (Hôpital Antoine, Béclère, Clamart France), Marie Thuong (ICU, Hôpital Delafontaine, Saint Denis, France), Guillaume Thierry (ICU, Hôpital Saint-Louis, Paris, France), Dany Toledano (CH Gonnesse, France), Gilles Troché (Medical surgical ICU, André Mignot Hospital, Versailles-Le Chesnay, France) and Eric Vantalon (SICU, Hôpital Saint-Joseph, Paris, France).

Study monitors: Caroline Tournegros, Loic Ferrand, Nadira Kaddour, Boris Berthe, Samir Bekkhouche, Kaouttar Mellouk.

\section{Author details}

${ }^{1}$ University of Grenoble 1 (Joseph Fourier) Integrated Research Center U 823 - Albert Bonniot Institute, Rond Point de la Chantourne 38706, La Tronche Cedex, France. ${ }^{2}$ Department of Critical Care Medicine, Peter Lougheed Centre and University of Calgary, 3500 26th Street NE, Calgary, Alberta, Canada T1Y 6J4. ${ }^{3}$ Polyvalent ICU, Groupe Hospitalier St Joseph, 145 Rue Raymond Losserand 75014, Paris, France. ${ }^{4}$ Medical ICU, Gabriel Montpied University Hospital, 58 Rue Montalembert, 63003 Clermont Ferrand Cedex 1, France. ${ }^{5}$ Medical ICU, University Hospital St Louis, 1 Avenue Claude Vellefaux, 75010, Paris, France. ${ }^{6}$ Polyvalent ICU, Gonesse General Hospital, 25 Rue

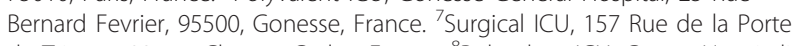
de Trivaux, 92141, Clamart Cedex, France. ${ }^{8}$ Polyvalent ICU, Centre Hospitalier Sud Essonne Dourdan-Etampes - Siège, 26 Avenue Charles de Gaulle, 91150, Etampes, France. 'Intensive care unit, Centre Hospitalier Andrée Rosemon, Av des Flamboyants, BP 6006 97306, Cayenne, France. ${ }^{10}$ Medical-Surgical ICU, Avicenne University Hospital, 125 Rue de Stalingrad, 93009, Bobigny Cedex, France. ${ }^{11}$ Medical polyvalent ICU, Grenoble University Hospital, BP217, 38043 Grenoble Cedex 9, France. ${ }^{12}$ Medical ICU, University Hospital Bellevue, 25 Boulevard Pasteur, 42100, Saint Etienne, France.

\section{Authors' contributions}

$\mathrm{KL}$ and JFT conceived the study and $\mathrm{KL}$ and $\mathrm{AV}$ performed the data extraction and the statistical analyses. $\mathrm{KL}$ wrote the draft version of the manuscript and BM, BS, AT, EA, DGT, ASD, SJ, HK, CC, MD, JFT are clinical investigators of the Outcomerea study groups and critically revised the draft manuscript. All the authors approved the final submission.

\section{Competing interests}

The authors declare that they have no competing interests.

Received: 24 June 2011 Accepted: 24 November 2011

Published: 24 November 2011

\section{References}

1. Bell CM, Redelmeier DA: Mortality among patients admitted to hospitals on weekends as compared with weekdays. N Engl J Med 2001, 345(9):663-668.

2. Cavallazzi R, Marik PE, Hirani A, Pachinburavan M, Vasu TS, Leiby BE: Association between time of admission to the ICU and mortality: a systematic review and metaanalysis. Chest 2010, 138(1):68-75.

3. Kuijsten HA, Brinkman S, Meynaar IA, Spronk PE, van der Spoel J, Bosman RJ, de Keizer NF, Abu-Hanna A, de Lange DW: Hospital mortality is associated with ICU admission time. Intensive Care Med 2010, 36(10):1765-1771. 
4. Kevat DA, Davies AR, Cameron PA, Rajaratnam SM: Increased mortality associated with after-hours and weekend admission to the intensive care unit: a retrospective analysis. Med J Aust 2011, 194(11):616.

5. Obel N, Schierbeck J, Pedersen L, Storgaard M, Pedersen C, Sorensen HT, Hansen B: Mortality after discharge from the intensive care unit during the early weekend period: a population-based cohort study in Denmark. Acta Anaesthesiol Scand 2007, 51(9):1225-1230,

6. Uusaro A, Kari A, Ruokonen E: The effects of ICU admission and discharge times on mortality in Finland. Intensive Care Med 2003, 29(12):2144-2148.

7. Goldfrad C, Rowan K: Consequences of discharges from intensive care at night. Lancet 2000, 355(9210):1138-1142.

8. Duke GJ, Green JV, Briedis JH: Night-shift discharge from intensive care unit increases the mortality-risk of ICU survivors. Anaesth Intensive Care 2004, 32(5):697-701.

9. Pilcher DV, Duke GJ, George C, Bailey MJ, Hart G: After-hours discharge from intensive care increases the risk of readmission and death. Anaesth Intensive Care 2007, 35(4):477-485.

10. Laupland KB, Shahpori R, Kirkpatrick AW, Stelfox HT: Hospital mortality among adults admitted to and discharged from intensive care on weekends and evenings. J Crit Care 2008, 23(3):317-324.

11. Outcomerea. Promotion et Development de la Recherche et de l'Enseignement en Reanimation (French). [http://www.outcomerea.org.], Accessed January 31, 2011.

12. Le Gall JR, Lemeshow S, Saulnier F: A new Simplified Acute Physiology Score (SAPS II) based on a European/North American multicenter study. JAMA 1993, 270(24):2957-2963.

13. Knaus WA, Draper EA, Wagner DP, Zimmerman JE: APACHE II: a severity of disease classification system. Crit Care Med 1985, 13(10):818-829.

14. American College of Chest Physicians/Society of Critical Care Medicine Consensus Conference: definitions for sepsis and organ failure and guidelines for the use of innovative therapies in sepsis. Crit Care Med 1992, 20(6):864-874.

15. MacFarlane $A$ : Variations in number of births and perinatal mortality by day of week in England and Wales. Br Med J 1978, 2(6153):1670-1673.

16. Mangold WD: Neonatal mortality by the day of the week in the 1974-75 Arkansas live birth cohort. Am J Public Health 1981, 71(6):601-605.

17. Priestap FA, Martin CM: Impact of intensive care unit discharge time on patient outcome. Crit Care Med 2006, 34(12):2946-2951.

18. Garrouste-Orgeas M, Montuclard L, Timsit JF, Reignier J, Desmettre T, Karoubi P, Moreau D, Montesino L, Duguet A, Boussat S, et al: Predictors of intensive care unit refusal in French intensive care units: a multiplecenter study. Crit Care Med 2005, 33(4):750-755.

\section{Pre-publication history}

The pre-publication history for this paper can be accessed here: http://www.biomedcentral.com/1472-6963/11/321/prepub

doi:10.1186/1472-6963-11-321

Cite this article as: Laupland et al: Mortality associated with timing of admission to and discharge from ICU: a retrospective cohort study. BMC Health Services Research 2011 11:321.

\section{Submit your next manuscript to BioMed Central and take full advantage of:}

- Convenient online submission

- Thorough peer review

- No space constraints or color figure charges

- Immediate publication on acceptance

- Inclusion in PubMed, CAS, Scopus and Google Scholar

- Research which is freely available for redistribution

Submit your manuscript at www.biomedcentral.com/submit 